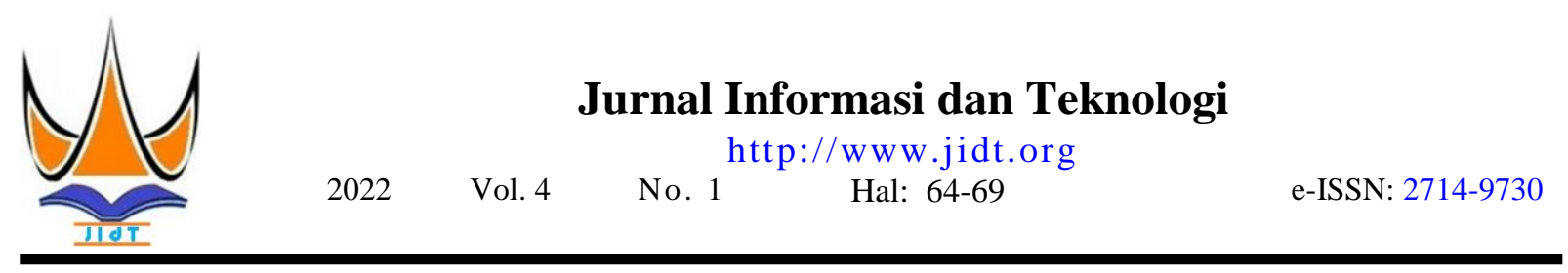

\title{
Tingkat Pemahaman Mahasiswa antar Pembelajaran Online dan Offline dalam Masa Pandemi Covid-19 Menggunakan Metode Forward Chaining
}

\author{
Alfina Tiurmida Sitanggang ${ }^{1 凶}$, Yenny Desnelita ${ }^{2}$ \\ ${ }^{1,2}$ Institut Bisnis dan Teknologi Pelita Indonesia \\ a1finatiurmida@gmai1.com
}

\begin{abstract}
Advances in science and technology have changed this world. One of the data technologies that function in the world of learning during the COVID-19 pandemic is online education. Online education is used as a liaison between lecturers and students in an internet network that is accessed anytime. However, student learning outcomes in online and offline learning have not shown maximum results. Various obstacles arise that affect student learning outcomes online and offline during the COVID-19 pandemic. This study aims to predict the level of student understanding in online and offline learning. So that it can also help Pelita Indonesia universities to take the right policies to improve the quality of learning in the future. To solve the various problems above, an expert system is needed to predict. In the expert system used is the forward chaining method. The forward chaining method is a method that performs forward tracking, starting from a collection of facts and ending at a conclusion. So that the accuracy value is obtained. With the results of the accuracy test, it determines the level of understanding between online and offline learning.
\end{abstract}

Keywords: Understanding, Online, Offline, Learning, Forward Chaining.

\begin{abstract}
Abstrak
Kemajuan Ilmu pengetahuan dan Teknologi sudah mengubah dunia ini. Salah satu teknologi data yang berfungsi dalam dunia pembelajaran pada masa pandemi COVID-19 yaitu pendidikan secara online. Pendidikan online digunakan selaku penghubung dosen dengan mahasiswa dalam satu jaringan internet yang diakses kapan saja. Namun hasil belajar mahasiswa dalam pembelajaran online dan ofline belum menunjukkan hasil yang maksimal. Berbagai kendala muncul sehingga mempengaruhi hasil belajar mahasiswa secara online dan ofline dimasa pandemi COVID-19. Penelitian ini bertujuan untuk memprediksi tingkat pemahaman mahasiswa dalam pembelajaran online dan ofline. Sehingga dapat pula membantu perguran tinggi Pelita Indonesia untuk mengambil kebijakan yang tepat untuk meningkatkan kualitas pembelajaran untuk kedepannya. Untuk menyelesaikan berbagai permasalahan diatas, maka diperlukan sistem pakar untuk menentukan keputusan dari pakar. Dalam sistem pakar yang digunakan adalah metode forward chaining. Metode forward chaining adalah metode yang melakukan pelacakan kedepan, dimulai dari kumpulan fakta dan berakhir dikesimpulan. Sehingga diperoleh nilai akurasi. Dengan hasil pengujian akurasi menentukan tingkat pemahaman antar pembelajaran secara online dan ofline.
\end{abstract}

Kata kunci: Pemahaman, Pembelajaran, Online,Offline, Forward Chaining.

(C) 2022 JIdT

\section{Pendahuluan}

Perkembangan teknologi informasi dan komunikasi kini semakin banyak dikembangkan serta dimanfaatkan di berbagai bidang aspek kehidupan guna menciptakan kemudahan dan efesiensi dalam menyelesaikan tugas suatu pekerjaan manusia. Khususnya di dunia pendidikan, teknologi sangat membantu dalam menunjang segala kegiatan pembelajaran sehingga mempermudah dosen dalam memberikan pembelajaran kepada mahasiswa. Pembelajaran secara online merupakan solusi terbaik terhadap kegiatan belajar mengajar ditengah pandemi COVID-19. Model pendidikan ini bertujuan untuk peningkatan akses untuk mahasiswa agar mendapatkan pendidikan yang lebih baik.

Institut bisnis dan teknologi pelita Indonesia telah melaksanakan pembelajaran di masa pandemi Covid-
19. Proses pembelajaran dilakukan secara online dan offline. Namun pembelajaran belum terlaksana dengan optimal sehingga Dosen kesulitan untuk mengukur tingkat pemahaman hasil belajar online maupun offline. Maka penting untuk menentukan guna mengukur tingkat pemahaman hasil belajar siswa, agar satuan pendidikan dapat mengambil kebijakan yang tepat untuk meningkatkan kualitas pembelajaran di masa yang akan datang.

Sistem ini sudah pernah diterapkan salah satunya penelitian mengenai Tingkat Pemahaman Siswa dalam Pembelajaran Daring dan Tatap Muka Langsung dalam masa Pandemi COVID-19 terhadap bimbingan TIK menggunakan Metode Backpropagation. Hasil peenelitian ini tahapan proses penelitian mengenai tingkat pemahaman siswa dalam pembelajaran daring dan tatap muka langsung dalam masa pandemi 
Covid19, maka disimpulkan bahwa Metode Backpropagation dapat digunakan untuk memprediksi tingkat pemahaman siswa terhadap bimbingan TIK dengan pola arsitektur 5-10-1 dengan tingkat akurasi yaitu $95 \%$. Sehingga penelitian ini dapat dijadikan rekomendasi dalam penentuan tingkat pemahaman siswa di masa yang akan datang [1].

Adapun penelitian ini adalah dapat menentukan modalitas belajar virtual, auditory dan kinesthetic. Modalitas belajar diolah menggunakan Sistem Pakar yang dibuat dengan bahasa pemograman php dan database MySQL. Sistem ini dapat membantu guru dan siswa dalam meningkatkan cara belajar siswa yang tepat [2].

Sistem Pakar adalah bidang dalam kecerdasan buatan yang dimaksudkan untuk berfungsi sebagai konsultan untuk pengambilan keputusan. Ini menggunakan kumpulan fakta, aturan praktis, dan pengetahuan lain tentang domain terbatas untuk membantu membuat kesimpulan dalam domain. Disebut Sistem Pakar karena mengatasi masalah yang biasanya dianggap membutuhkan spesialis manusia untuk solusinya. Sistem pakar dapat dipandang memiliki dua lingkungan: lingkungan pengembangan dan lingkungan konsultasi. Lingkungan pengembangan digunakan oleh pembangun Sistem Pakar untuk membangun komponen dan memasukkan pengetahuan ke dalam basis pengetahuan. Lingkungan konsultasi digunakan oleh nonahli untuk memperoleh pengetahuan dan saran ahli [3].

Berdasarkan peelitian media pembelajaran media pembelajaran ini dibuat berbasis web karena dapat diakses oleh siswa secara online untuk menunjang proses pembelajaran secara online, terutama di masa pandemi ini. Berdasarkan hasil pengujian perbandingan sistem dapat disimpulkan bahwa media pembelajaran identifikasi kerusakan mesin pesawat ini dapat menghasilkan solusi yang sesuai dengan kondisi yang tepat. Media ini juga mendukung pembelajaran online karena media berbasis web dapat mengakses internet kapan saja dan dimana saja [4]

Forward Chaining adalah model komputasi bottom-up. Forward Chaining bekerja dengan seperangkat fakta yang diketahui dan menerapkan aturan untuk menghasilkan fakta baru yang premisnya cocok dengan fakta yang diketahui, dan berlanjut hingga mencapai tujuan yang telah ditentukan, atau sampai tidak ada fakta lebih lanjut yang dapat diturunkan yang premisnya cocok dengan fakta yang diketahui [5].

\section{Metodologi Penelitian}

Pada metodologi penelitian ini merupakan langkahlangkah kerja, yang perlu dilakukan agar penyusunan penelitian menjadi lebih mudah dan juga dapat digunakan sebagai pedoman dalam melaksanakan penelitian. Adapun bentuk uraian kerangka kerja dalam penelitian ini diawali dengan mengidentifikasi masalah, menganalisis masalah, menentukan tujuan, mempelajari literature, pengumpulan data, menganalisis data, desain sistem, implementasi sistem dan pengujian sistem. Tahap-tahap kerangka kerja dibuat agar penelitian menjadi terarah dan mencapai tujuan yang ditentukan dalam penelitian ini. Tujuan penelitian ini yakni untuk mengidentifikasi karakter pemahaman pembelajaran mahasiswa menggunakan metode Forward Chaining.

Dalam proses penelitian ini, diperlukan literatur untuk pemahaman konsep dan pendalaman materi dari beberapa jurnal sebagai referensi. Tahap selanjutnya adalah teknik pengumpulan data dengan cara observasi secara langsung. Metodologi penelitian ini merupakan langkah-langkah kerja yang perlu dilakukan agar penyusunan penelitian menjadi lebih mudah dan juga dapat digunakan sebagai pedoman untuk penelitian dalam melakukan penelitian. Metodologi yang digunakan dalam penelitian ini diperlihatkan dalam suatu kerangka kerja yang akan dijelaskan pada penelitian ini. Kerangka kerja adalah suatu struktur konseptual dasar yang digunakan untuk memecahkan atau menangani suatu masalah kompleks, maka dapat dituliskan mengenai metode yang digunakan dalam penelitian ini pada Gambar 1.

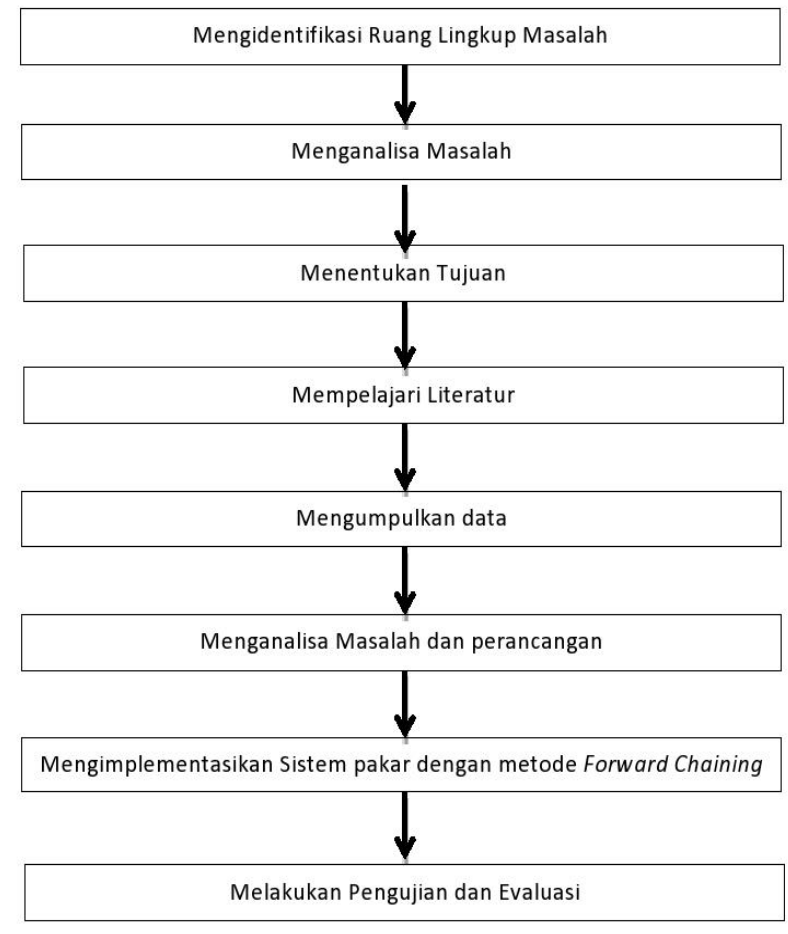

Gambar 1. Kerangka Kerja Penelitian

a. Mengidentifikasi Ruang Lingkup Masalah

Tahapan ini merupakan tahapan awal untuk menentukan rumusan masalah yang terjadi pada pembelajaran mahasiswa yaitu penerapan metode Forward Chaining dalam menentukan menentukan tingkat pemahaman mahasiswa antara pembelajaran online dan offline dalam masa pandemi Covid-19, 
yang mana dilakukan peninjauan sistem yang akan diteliti untuk mengamati serta melakukan pertanyaan dan menggali permasalahan yang ada pada sistem yang berjalan nanti.

\section{b. Menganalisa Masalah}

Langkah analisis masalah merupakan untuk dapat memahami masalah yang telah ditentukan ruang lingkup atau batasannya. Dengan menganalisa masalah yang telah ditentukan tersebut, maka diharapkan masalah dapat dipahami dengan baik. Pada analisa masalah ini digambarkan proses untuk menentukan pemahaman belajar mahasiswa yang akan terjadi pada masa pandemi online dan offline.

\section{c. Menentukan Tujuan}

Tujuan penelitian merupakan suatu hal yang akan dicapai dalam suatu penelitian yang dilakukan. Tujuan peneliti ini merupakan hasil akhir ideal yang diharapkan tercapai setelah penelitian tersebut dilakukan. Tujuan penelitian harus ditentukan diawal terlebih dahulu sebelum penelitian dilakukan.

\section{d. Mempelajari Literatur}

Untuk mencapai tujuan maka dipelajari beberapa literature-literatur yang diperkirakan dapat digunakan. Kemudian literatur-literatur yang dipelajari tersebut diseleksi untuk dapat ditentukan literatur mana yang akan digunakan dalam penelitian. Literatur diambil dari beberapa sumber yaitu artikel, jurnal ilmia tentang simulasi Forward Chaining, serta bacaan lain yang mendukung.

\section{e. Mengumpulkan Data}

Mengumpulkan data merupakan tindakan yang dilakukan untuk mengumpulkan semua data-data yang diperlukan dalam penelitian. Pengumpulan data dalam penelitian ini merupakan data skunder yaitu penelulusuran terhadap pertanyaan yang ada untuk mendapatkan data pembelajaran online dan offline masa pendemi.

\section{f. Menganalisa Masalah dan Perancangan}

Pada tahap ini akan dilakukan analisa dan perancangan teradap permasalahan yang ada berdasarkan data-data yang telah dikumpulkan dengan tahapan-tahapan yang ada dalam metode Forward Chaining.

\section{g. Mengimplementasikan Sistem Pakar dengan Metode Forward Chaining}

Sistem Pakar dengan Metode Forward Chaining diterapkan dengan bahasa pemograman PHP Dalam membangun sebuah sistem yang berbasis komputerisasi ada 2 komponen yang dipenuhi yaitu hardware dan software.

h. Melakukan Pengujian Sistem Pakar Forward Chaining dan Evaluasi
Pengujian Sistem Pakar dengan metode Forward Chaining ini dilakukan untuk memastikan apakah aplikasi Sistem Pakar yang dirancang. Sudah mencapai tujuan yang diinginkan dan apakah sudah layak untuk diimplementasikan kepada user.

\section{Hasil dan Pembahasan}

\subsection{Basis Pengetahuan}

Representasi pengetahuan yang diperoleh dari pakar tersebut adalah berupa data karakter pemahaman pembelajaran mahasiswa. Disini data yang digunakan dan didapatkan berjumlah 2 jenis pembelajaran serta anjuran dan strategi sesuai dengan karakter pemahaman pembelajaran yang diperoleh dari pakar dapat dilihat pada Tabel 1.

Tabel 1. Karakter Pemahaman Pembelajaran Mahasiswa

\begin{tabular}{|c|c|c|}
\hline Kode & Karakter & Jenis \\
\hline K01 & $\begin{array}{ll}\text { Memilih media } & \text { pembelajaran } \\
\text { menggunakan aplikasi } & \end{array}$ & Online \\
\hline K02 & Memilih pembelajaran diruang kelas & Offline \\
\hline K03 & $\begin{array}{l}\text { Suka diajari oleh dosen dengan cara } \\
\text { memberikan materi digoogle class } \\
\text { room. }\end{array}$ & Online \\
\hline K04 & $\begin{array}{l}\text { Suka diajari oleh dosen dengan cara } \\
\text { memberikan materi secara langsung. }\end{array}$ & Offline \\
\hline K05 & $\begin{array}{l}\text { Mudah berdiskusi kelompok } \\
\text { menggunakan zoom. }\end{array}$ & Online \\
\hline K06 & $\begin{array}{l}\text { Mudah berdiskusi kelompok secara } \\
\text { langsung dengan kelompok }\end{array}$ & Offline \\
\hline K07 & $\begin{array}{l}\text { Membutuhkan Jaringan atau biaya } \\
\text { kuota saat belajar. }\end{array}$ & Online \\
\hline K08 & $\begin{array}{l}\text { Membutuhkan BiayaTransportasi ke } \\
\text { kampus. }\end{array}$ & Offline \\
\hline K09 & $\begin{array}{l}\text { Kesulitan dalam perkuliahan pratikum } \\
\text { saat menggunakan aplikasi belajar. }\end{array}$ & Online \\
\hline K10 & $\begin{array}{l}\text { Suka dalam perkuliahan pratikum } \\
\text { dengan fasilitas yang lengkap di ruang } \\
\text { kelas. }\end{array}$ & Offline \\
\hline K11 & $\begin{array}{l}\text { Tidak Konsentrasi terhadao gangguan } \\
\text { suara menggunakan aplikasi belajar. }\end{array}$ & Online \\
\hline K12 & $\begin{array}{l}\text { Tidak mudah terganggu oleh keributan } \\
\text { saat di ruangan kelas. }\end{array}$ & Offline \\
\hline K13 & $\begin{array}{l}\text { Mudah memahami pembelajaran dari } \\
\text { media aplikasi pembelajaran }\end{array}$ & Online \\
\hline K14 & $\begin{array}{l}\text { Mudah memahami pembelajaran di } \\
\text { ruang kelas lebih focus. }\end{array}$ & Offline \\
\hline K15 & $\begin{array}{l}\text { Suka dengan Metode Penyelenggaraan } \\
\text { Ujian (UTS) dari implementasi daring }\end{array}$ & Online \\
\hline K16 & $\begin{array}{l}\text { Suka dengan metode penyelenggaraan } \\
\text { Ujian (UTS) ketersediaan dari kampus } \\
\text { secara langsung }\end{array}$ & Offline \\
\hline
\end{tabular}

\subsection{Inference Engine (Mesin inferensi)}

Teknik yang digunakan dalam perancangan sistem pakar ini menggunakan metode forward chaining atau biasa juga disebut ini lebih cocok diterapkan untuk memperoleh hasil identifikasi pemahaman antar pembelajaran mahasiswa. Pengumpulan data dilakukan dengan cara melihat karakter pemahaman antar pembelajaran hingga memperoleh suatu kesimpulan dari permasalahan-permasalahan yang ada serta anjuran untuk mahasiswa dan strategi untuk dosen. Berikut ini implementasi kedalam bahasa pemograman PHP dengan menggunakan database MySQL. 
a. Data

Untuk mendapatan informasi dan data-data yang valid maka dilakukan wawancara dengan pakar tim LPPM yang dilakukan di Intitut Bisnis dan Teknologi Pelita Indonesia.

\section{b. Pencocokan karakter}

Berdasarkan variable yang akan ada diatas karakter pemahaman antar pembelajaran bisa dikelompokkan berdasarkan penalaran beberapa karakter pemahaman antar pembelajaran melalui pohon keputusan.

c. Pencocokan karakter yang muncul

Dari pengelompokan diatas dilakukan pencocokan pada karakter dan jenis pembelajaran dengan membuat tabel decision yang disajikan pada Gamabr 2 dan Tabel 2.

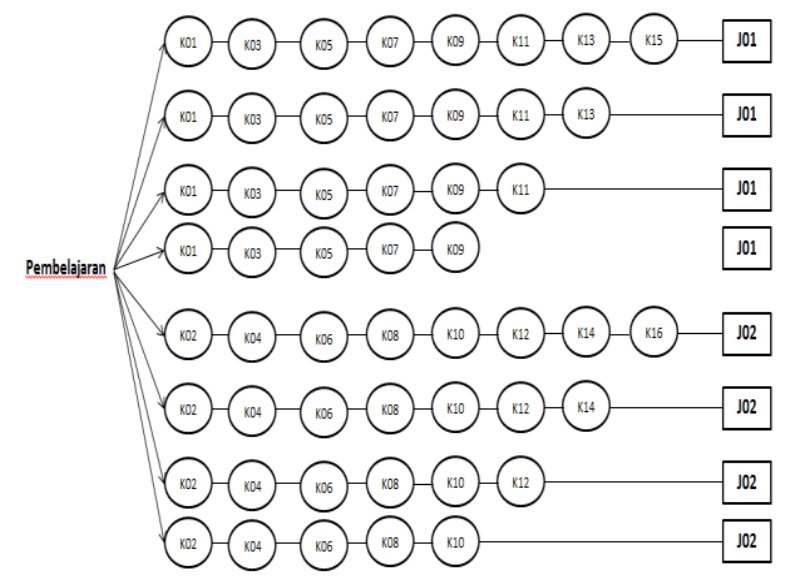

Gambar 2. Pohon Keputusan

Tabel 2. Identifikasi Karakter

\begin{tabular}{lcc}
\hline Kode & J01 & J02 \\
\hline KO1 & X & X \\
K02 & & \\
K03 & X & X \\
K04 & & \\
K05 & X & X \\
K06 & & \\
K07 & X & X \\
K08 & & \\
K09 & X & X \\
K10 & & \\
K11 & X & X \\
K12 & & \\
K13 & X & X \\
K14 & & \\
K15 & X & X \\
K16 & &
\end{tabular}

\section{d. Hasil Identifikasi}

Berdasarkan penyajian fakta dan proses yang sudah dijelaskan di atas, untuk perancangan dan perencanaan identifikasi pertanyaan pemahaman antar pembelajaran, maka disusun daftar aturan (rule) yang sesuai dengan prosedur dengan menggunakan ekspresi logika, untuk lebih jelasnya dapat dilihat pada Tabel 3.
Tabel 3. Rule

\begin{tabular}{ll}
\hline No & Aturan \\
\hline 1. & IF K01 IS True AND K03 IS True AND K05 IS True \\
& AND K07 IS True AND K09 IS True AND K11 IS \\
& True AND K13 IS True AND 15 Then IS J01 \\
2. & IF K01 IS True AND K03 IS True AND K05 IS True \\
& AND K07 IS True AND K09 IS True AND K11 IS \\
True AND K13 Then IS J01 \\
IF K01 IS True AND K03 IS True AND K05 IS True \\
AND K07 IS True AND K09 IS True AND K11 \\
Then IS J01 \\
IF K01 IS True AND K03 IS True AND K05 IS True \\
AND K07 IS True AND K09 Then IS J01 \\
IF K02 IS True AND K04 IS True AND K06 IS True \\
AND K08 IS True AND K10 IS True AND K12 IS \\
True AND K14 IS True AND K16 Then IS J02 \\
IF K02 IS True AND K04 IS True AND K06 IS True \\
AND K08 IS True AND K10 IS True AND K12 IS \\
True AND K14 Then IS J02 \\
IF K02 IS True AND K04 IS True AND K06 IS True \\
AND K08 IS True AND K10 IS True AND K12 \\
Then IS J02 \\
IF K02 IS True AND K04 IS True AND K06 IS True \\
AND K08 IS True AND K10 Then IS J02 \\
IF K02 IS True AND K04 IS True AND K06 IS True \\
AND K08 Then IS J02
\end{tabular}

Dalam implementasi sistem diperlukan aplikasi Sistem Pakar untuk mngidentifikasi karakter pemahaman antar pembelajaran dengan menggunakan Bahasa Pemograman PHP dan database MySQL.

Halaman utama adalah tampilan yang pertama kali muncul pada saat mengakses sistem. Pada halaman ini terdapat pilihan home, mahasiswa, Pertanyaan, Rule, Rekap, User. Dimana admin atau mahasiswa dapat akses menu utama yang disajikan pada Gamabr 3 .

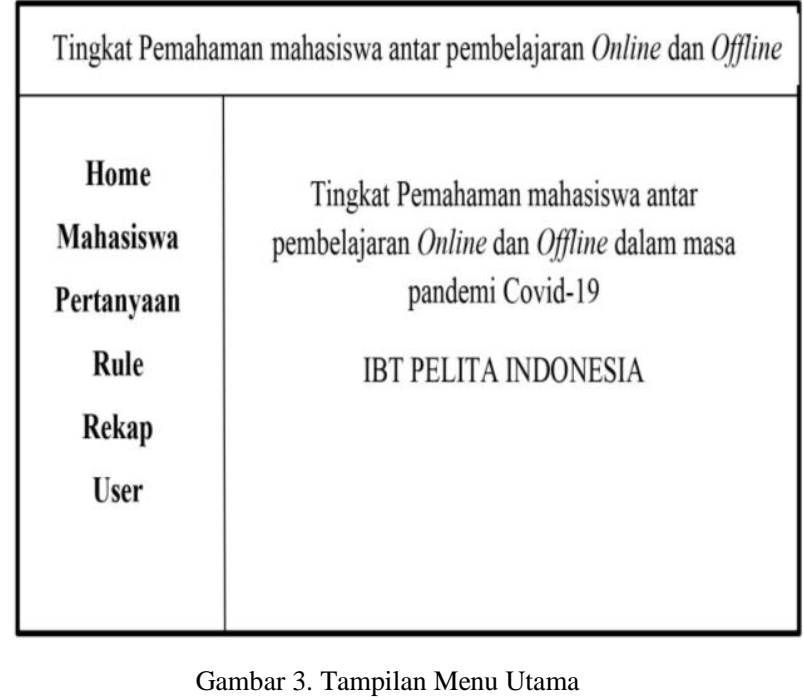

Halaman menu mahasiswa adalah menu pendafaran atau registrasi berguna bagi mahasiswa. Tampilan yang pertama kali muncul pada saat mengakses sistem. Pada halaman ini terdapat isian pendaftaran data mahasiswa yang sesuai dengan data masing-masing yang disajikan pada Gambar 4. 


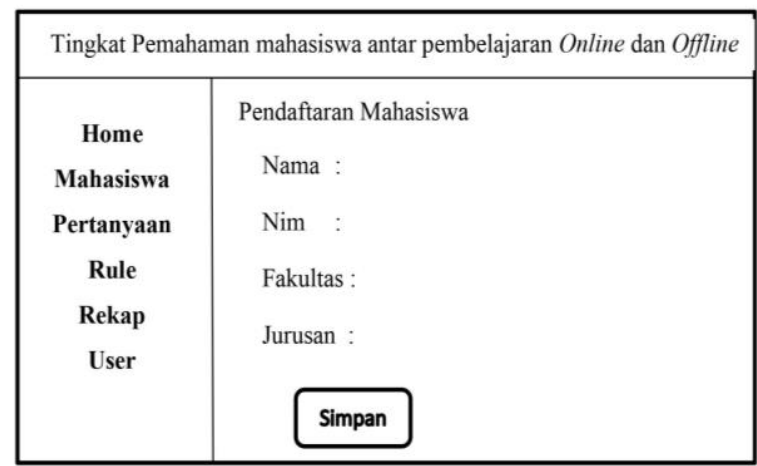

Gambar 4. Tampilan Menu Utama

Halaman rule adalah tampilan pada halaman ini terdapat pilihan home, mahasiswa, Pertanyaan, Rule, Rekap, User. Dimana admin atau mahasiswa dapat akses menu rule, kode rule, jenis yang disajikan pada Gamabr 5.

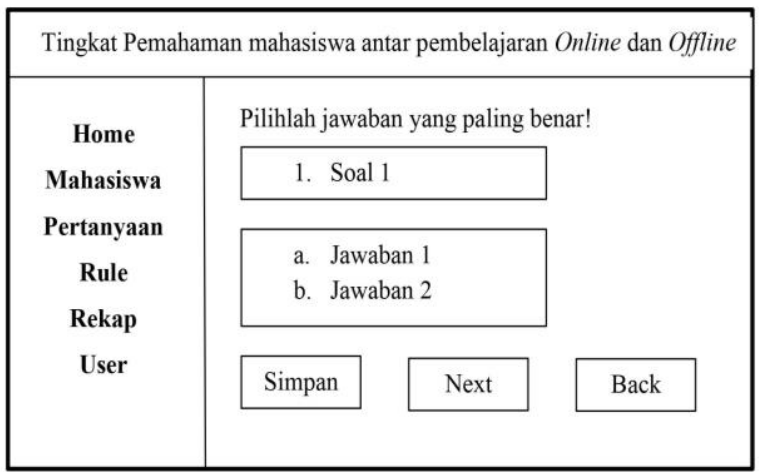

Gambar 5. Tampilan Menu Pertanyaan

Halaman rule adalah tampilan pada halaman ini terdapat pilihan home, mahasiswa, Pertanyaan, Rule, Rekap, User. Dimana admin atau mahasiswa dapat akses menu rule, kode rule, jenis yang disajikan pada Gambar 6.

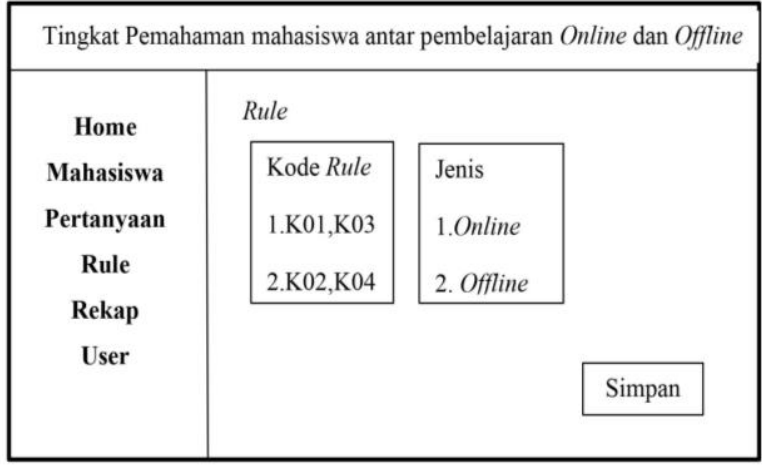

Gambar 6. Tampilan Menu Rule

Halaman rekap adalah tampilan yang berisi hasil pemahaman mahasiswa antar pembelajaran Online dan Offline, dapat menghasilkan nilai dan diagram penentuan pembelajaran online dan offline. Data sudah tersimpan ke database yang disajikan pada Gamabr 7.

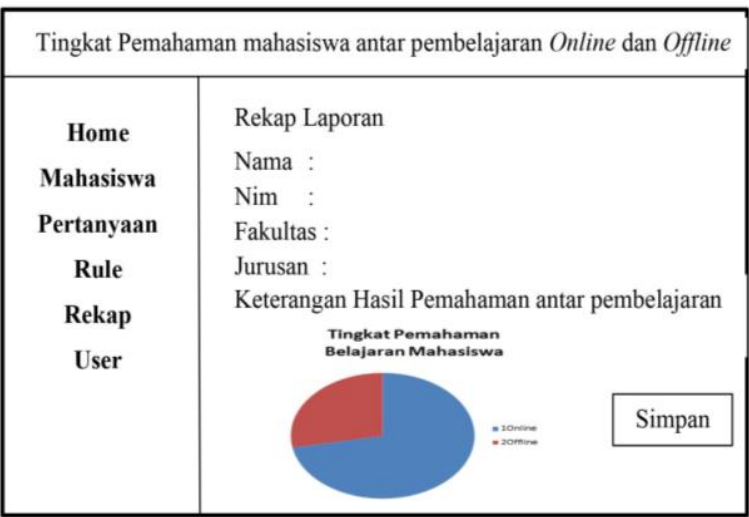

Gambar 7. Tampilan Menu Rekap

Hasil uji coba yang dilakukan kepada 50 orang mahasiswa dengan menggunakan alikasi Sistem Pakar ini 40 orang hasil $80 \%$ memilih pembelajaran offline dan 20 orang hasil $20 \%$ memilih pembelajaran online

\section{Kesimpulan}

Sistem Pakar dengan Metode Forward Chaining telah mampu mengidentifikasi pemahaman pembelajaran mahasiswa dengan jelas. Sistem pakar ini dapat membantu mahasiswa dalam menentukan jenis pemahaman pembelajaran. Hasil pengujian didapatkan tingkat akurasi sebesar $80 \%$ offline dan online $20 \%$, sehingga penelitian ini menjadi rujukan dalam penentuan pembelajaran yang tepat, apakah online atau offline.

\section{Daftar Rujukan}

[1]. Salmiati, S., Yunus, Y., \& Sumijan, S. (2021). Tingkat Pemahaman Siswa dalam Pembelajaran Daring dan Tatap Muka Langsung dalam Masa Pandemi Covid-19 Terhadap Bimbingan TIK Menggunakan Metode Backpropagation. Jurnal Sistim Informasi Dan Teknologi, 95-101. doi:10.37034/jsisfotek.v3i3.129

[2]. Kurniawan, A., Sumijan, \& Jufriadif Na'am. (2019). Sistem Pakar Identifikasi Modalitas Belajar Siswa Menggunakan Metode Forward Chaining. Jurnal RESTI (Rekayasa Sistem Dan Teknologi Informasi), 3(3), 518-523. doi:10.29207/resti.v3i3.1166

[3]. Irmayani,D.(2019). Sistem Pakar Penelusuran Kecerdasan Pada Anak dengan Menggunakan Metode Forward Chaining. Jurnal Informatika, 5(2), 1-20. doi:10.36987/informatika.v5i2.725

[4]. Ayuningtyas, A., Honggowibowo, A. S., Mulyani, S., \& Priadana, A. (2020). A Web-Based Aircraft Maintenance Learning Media to Support Learning Process in Aerospace Engineering Education during the COVID-19 Pandemic. 2020 Sixth International Conference on e-Learning (econf). doi:10.1109/econf51404.2020.9385520

[5]. Wahyuni, T. (2016). Sistem Pakar untuk mengidentifikasi Masalah psikologi Remaja menggunakan Metode Inferensi Forward Chaining Brbasis Android. J-ENSITEC, 2(02). doi:10.31949/j-ensitec.v2i02.304

[6]. Laidawati, D., \& Yuhandri, Y. (2019). Sistim Pakar Konseling Mata Pelajaran Pilihan UNBK Menggunakan Metode Forward Chaining. Jurnal Sistim Informasi Dan Teknologi, 1(3), 1-6. doi:10.35134/jsisfotek.v1i3.2

[7]. Harjanto, A., Karnila, S., \& Nugraha, F. (2018). Rancangan Bangun Aplikasi Sistem Pakar Untuk Konsultasi Perilaku 
Siswa di Sekolah Menggunakan Metode Forward Chaining. Simetris: Jurnal Teknik Mesin, Elektro Dan Ilmu Komputer, 9(2), 817-824. doi:10.24176/simet.v9i2.2367

[8]. Mulyani, E. D. S., Hidayat, C. R., \& Ulfa, T. C. (2021). Sistem Pakar Untuk Menentukan Jurusan Kuliah Berdasarkan Minat dan Bakat Siswa SMA Dengan Menggunakan Metode Forward Chaining. CSRID (Computer Science Research and Its Development Journal), 10(2), 80. doi:10.22303/csrid.10.2.2018.80-92

[9]. Yuliana, Y. (2021). Sitem Pakar Diagnosis Kerusakan Mesin FotoCopy Minolta CS PRO EP5000 Dengan Menggunakan Metode Forward Chaining. Jurnal Perangkat Lunak, 3(2), 51-59. doi:10.32520/jupel.v3i2.1622

[10]. Waliyansyah, R. R., Novita, M., \& Aditasar, L. P. (2020) Sistem Pakar Penentuan Gaya Belajar Siswa Dengan Metode Forward Chaining Berbasis Web. IT Journal Research and Development, $\quad 5(1), \quad 32-44$. doi:10.25299/itjrd.2020.vol5(1).4740

[11]. Kuswanto, J. (2020). Sistem Pakar Untuk Perlindungan Tanaman Padi Menggunakan Metode Forward Chaining. Edutic - Scientific Journal of Informatics Education, 7(1). doi:10.21107/edutic.v7i1.8805

[12]. Sugiharni, G. A. D., \& Divayana, D. G. H. (2017) Pemanfaatan Metode Forward Chaining Dalam Pengembangan Sistem Pakar Pendiagnosa Kerusakan Televisi Berwarna Jurnal Nasional Pendidikan Teknik Informatika (JANAPATI), 6(1), 20. doi:10.23887/janapati.v6i1.9926
[13]. Anwar, M. (2021). Designing an expert system for determining student learning styles using forward chaining in engineering education. Jurnal Konseling Dan Pendidikan, 9(1), 93. doi: $10.29210 / 159000$

[14]. Idris, M., Mustafid, \& Suseno, J.E. (2019). Implementation of C4.5 Algorithm and Forward Chaining Method for Higher Education Performance Analysis. E3S Web of Conferences.DOI:10.1051/e3sconf/201912521002

[15]. Aminanto, M. E., Ban, T., Isawa, R., Takahashi, T., \& Inoue, D. (2020). Threat Alert Prioritization Using Isolation Forest and Stacked Auto Encoder With Day-Forward-Chaining Analysis. IEEE Access, 8, 217977-217986. doi:10.1109/access.2020.3041837

[16]. Muludi, K., Suharjo, R., Syarif, A., \& Ramadhani, F. (2018). Implementation of forward chaining and certainty factor method on android-based expert system of tomato diseases identification. International Journal of Advanced Computer Science and Applications, 9, 451-456. Doi 10.14569/IJACSA.2018.090957

[17]. Ariandi, V., Kurnia, H., \& Hadi, A. F. (2019). Web-Based Expert System to Diagnose Gastroenteritis in Children in Pariaman District Hospital using the Forward Chaining Method. Jurnal KomtekInfo, 6(1), 108-112. doi:10.35134/komtekinfo.v6i1.46

[18]. Ramadhan, R. N., \& Suprianto. (2022). Expert System to Diagnose Soil and Plant Types According to The Web-Based Forward Chaining Method. Procedia of Engineering and Life Science, 2. doi:10.21070/pels.v2i0.1181 